\title{
Global-change effects on early-stage decomposition processes in tidal wetlands - implications from a global survey using standardized litter
}

Peter Mueller ${ }^{1}$, Lisa M. Schile-Beers ${ }^{2}$, Thomas J. Mozdzer ${ }^{3}$, Gail L. Chmura ${ }^{4}$, Thomas Dinter ${ }^{5}$, Yakov Kuzyakov ${ }^{5,6}$, Alma V. de Groot ${ }^{7}$, Peter Esselink ${ }^{8,9}$, Christian Smit ${ }^{9}$, Andrea D'Alpaos ${ }^{10}$, Carles Ibáñez ${ }^{11}$, Magdalena Lazarus ${ }^{12}$, Urs Neumeier $^{13}$, Beverly J. Johnson ${ }^{14}$, Andrew H. Baldwin ${ }^{15}$, Stephanie A. Yarwood ${ }^{15}$, Diana I. Montemayor ${ }^{16}$, Zaichao Yang ${ }^{17}$, Jihua $\mathrm{Wu}^{17}$, Kai Jensen ${ }^{1}$, and Stefanie Nolte ${ }^{1}$

${ }^{1}$ Applied Plant Ecology, Biocenter Klein Flottbek, Universität Hamburg, Ohnhorststraße 18, 22609 Hamburg, Germany

${ }^{2}$ Smithsonian Environmental Research Center, 647 Contees Wharf Rd, Edgewater, MD 21037, USA

${ }^{3}$ Department of Biology, Bryn Mawr College, 101 N. Merion Ave, Bryn Mawr, PA 19010, USA

${ }^{4}$ Department of Geography, McGill University, 805 Sherbrooke St W, QC H3A 0B9, Canada

${ }^{5}$ Department of Soil Science of Temperate Ecosystems, University of Göttingen, Büsgenweg 2, 37077 Göttingen, Germany

${ }^{6}$ Institute of Environmental Sciences, Kazan Federal University, 420049 Kazan, Russia

${ }^{7}$ Wageningen Marine Research, Wageningen University and Research, Ankerpark 27, 1781 AG Den Helder, the Netherlands

${ }^{8}$ PUCCIMAR, Boermarke 35, 9481 HD Vries, the Netherlands

${ }^{9}$ Conservation Ecology Group, Groningen Institute for Evolutionary Life Sciences, University of Groningen, P.O. Box 11103, 9700 CC Groningen, the Netherlands

${ }^{10}$ Department of Geosciences, University of Padova, Via Gradenigo 6, Padua 35131, Italy

${ }^{11}$ IRTA Aquatic Ecosystems, Carretera Poblenou Km 5.5, 43540 Sant Carles de Ràpita, Catalonia, Spain

${ }^{12}$ Department of Plant Taxonomy and Nature Conservation, University of Gdańsk, ul. Wita Stwosza 59,

80-308 Gdańsk, Poland

${ }^{13}$ Institut des sciences de la mer de Rimouski, Université du Québec à Rimouski, 310 allée des Ursulines, Rimouski QC G5L 3A1, Canada

${ }^{14}$ Department of Geology, Bates College, 214 Carnegie Sciences Building, Lewiston, ME 04240, USA

${ }^{15}$ Department of Environmental Science and Technology, University of Maryland, College Park, MD 20742, USA

${ }^{16}$ Instituto de Investigaciones Marinas y Costeras (IIMyC), CONICET, UNMDP, Mar del Plata, Argentina

${ }^{17}$ Ministry of Education Key Laboratory for Biodiversity Science and Ecological Engineering,

Institute of Biodiversity Science, Fudan University, Shanghai 200438, China

Correspondence: Peter Mueller (peter.mueller@uni-hamburg.de)

Received: 12 December 2017 - Discussion started: 15 December 2017

Revised: 24 April 2018 - Accepted: 26 April 2018 - Published: 30 May 2018

\begin{abstract}
Tidal wetlands, such as tidal marshes and mangroves, are hotspots for carbon sequestration. The preservation of organic matter $(\mathrm{OM})$ is a critical process by which tidal wetlands exert influence over the global carbon cycle and at the same time gain elevation to keep pace with sealevel rise (SLR). The present study assessed the effects of temperature and relative sea level on the decomposition rate and stabilization of OM in tidal wetlands worldwide, utilizing commercially available standardized litter. While effects
\end{abstract}

on decomposition rate per se were minor, we show strong negative effects of temperature and relative sea level on stabilization, as based on the fraction of labile, rapidly hydrolyzable OM that becomes stabilized during deployment. Across study sites, OM stabilization was $29 \%$ lower in low, more frequently flooded vs. high, less frequently flooded zones. Stabilization declined by $\sim 75 \%$ over the studied temperature gradient from 10.9 to $28.5^{\circ} \mathrm{C}$. Additionally, data from the Plum Island long-term ecological research site in Mas- 
sachusetts, USA, show a pronounced reduction in OM stabilization by $>70 \%$ in response to simulated coastal eutrophication, confirming the potentially high sensitivity of OM stabilization to global change. We therefore provide evidence that rising temperature, accelerated SLR, and coastal eutrophication may decrease the future capacity of tidal wetlands to sequester carbon by affecting the initial transformations of recent OM inputs to soil OM.

\section{Introduction}

Tidal wetlands, such as marshes and mangroves, provide a wide array of ecosystem services that have been valued at approximately USD 10000 per hectare and year, making them some of the most economically valuable ecosystems on earth (Barbier et al., 2011; Kirwan and Megonigal, 2013). Yet, tidal wetlands are threatened and vulnerable ecosystems, experiencing pronounced loss through global-change impacts, such as land use (Pendleton et al., 2012) and accelerated sea-level rise (SLR) (Craft et al., 2009; Crosby et al., 2016). In recent years, carbon sequestration has increasingly been recognized as an ecosystem service of tidal wetlands (Chmura et al., 2003; Mcleod et al., 2011). Here, high rates of organic matter (OM) input (from both autochthonous and allochthonous production) co-occur with reducing soil conditions and thus slow rates of decomposition, leading to long-term carbon-sequestration rates that exceed those of most other ecosystem types by an order of magnitude (Mcleod et al., 2011). At the same time, suppressed decomposition and the preservation of $\mathrm{OM}$ is a primary process by which many tidal wetlands gain elevation and keep pace with rising sea level (Kirwan and Megonigal, 2013). Consequently, global changes that decrease OM preservation in tidal-wetland soils not only affect carbon sequestration, but also decrease ecosystem stability against SLR. It is therefore critical to identify global-change factors that affect the transformation of organic inputs to stable soil OM (SOM) in tidal wetlands and to assess the magnitude of their effects.

There are multiple methods for assessing factors that influence carbon sequestration, including direct measurements of plant production, carbon stocks, accretion, and decomposition rates. Litter-bag techniques assessing the weight loss of plant material over time are probably the easiest way to measure decomposition rates in situ and have been widely used since the 1960s (Prescott, 2010). Global-scale assessments of litter decomposition have been conducted as both meta-analyses (e.g., Zhang et al., 2008) and as inter-site studies along latitudinal gradients (Berg et al., 1993; Cornelissen et al., 2007; McTiernan et al., 2003; Powers et al., 2009; Trofymow et al., 2002) in order to assess effects of climate parameters on decomposition rate. Besides abiotic or climate effects, these studies could also identify litter quality itself as an important predictor for decomposition rate
(Zhang et al., 2008). Relationships between single climate or litter-quality parameters and decomposition rate often are not linear. Instead, complex interactions between litter-quality and climate parameters seem to control litter decomposition (Zhang et al., 2008), creating challenges in separating climate from litter-quality effects and predicting the relevance of potential global-change drivers for decomposition rate. In order to separately assess environmental or climate effects on litter decomposition at a global scale, it is therefore necessary to standardize litter quality in inter-site studies. However, implications of litter-decay data for carbon sequestration need to be considered cautiously, as the link among litter-decomposition rate, SOM formation, and ultimately carbon sequestration is not straightforward (Cotrufo et al., 2013; Prescott, 2010): Because plant tissues are not resistant to decay per se, it is critical to understand their biogeochemical transformation into stable compounds that leads to the formation of SOM (i.e., stabilization) rather than understanding the pace at which early-stage decomposition proceeds (Castellano et al., 2015; Haddix et al., 2016; Prescott, 2010). Keuskamp et al. (2013) developed an efficient approach for studying litter decomposition and OM transformation at a global scale, using commercially available tea as standardized material. Their Tea Bag Index (TBI) approach is based on the deployment of two types of tea that considerably differ in their OM quality. The method allows for the determination of the decomposition rate constant (in the following referred to as decomposition rate or $k$ ) and a stabilization factor (in the following referred to as stabilization or $S$ ), which describes the fraction of labile and rapidly decomposable OM that becomes stabilized during deployment. In the present study, we assessed effects of the global-change factors global warming, accelerated SLR, and coastal eutrophication on both OM decomposition rate and stabilization in tidal-wetland soils by conducting a worldwide survey using standardized litter. First, by covering a large temperature gradient of $\Delta T>15^{\circ} \mathrm{C}$ across sites, we aimed to capture temperature effects on $\mathrm{OM}$ decomposition rate and stabilization, thereby improving our understanding on how global warming affects carbon turnover and ultimately sequestration in tidal wetlands. Second, by conducting paired measurements in both high and low elevated zones of tidal wetlands worldwide, we were aiming to gain insight into potential effects of accelerated SLR on carbon turnover. Despite the dominant paradigm that decomposition is inversely related to flooding, the existing literature on hydrology and SLR effects on OM decomposition in tidal wetlands yields equivocal results, which is often due to the overriding effect of OM quality on decomposition rate (Hemminga and Buth, 1991; Kirwan et al., 2013; Mueller et al., 2016). Lastly, we used the TIDE (Trophic cascades and Interacting control processes in a Detritus-based Ecosystem) project plots of the Plum Island long-term ecological research site in Massachusetts, USA (Deegan et al., 2012), to experimentally assess both the effects of coastal eutrophication and - with re- 


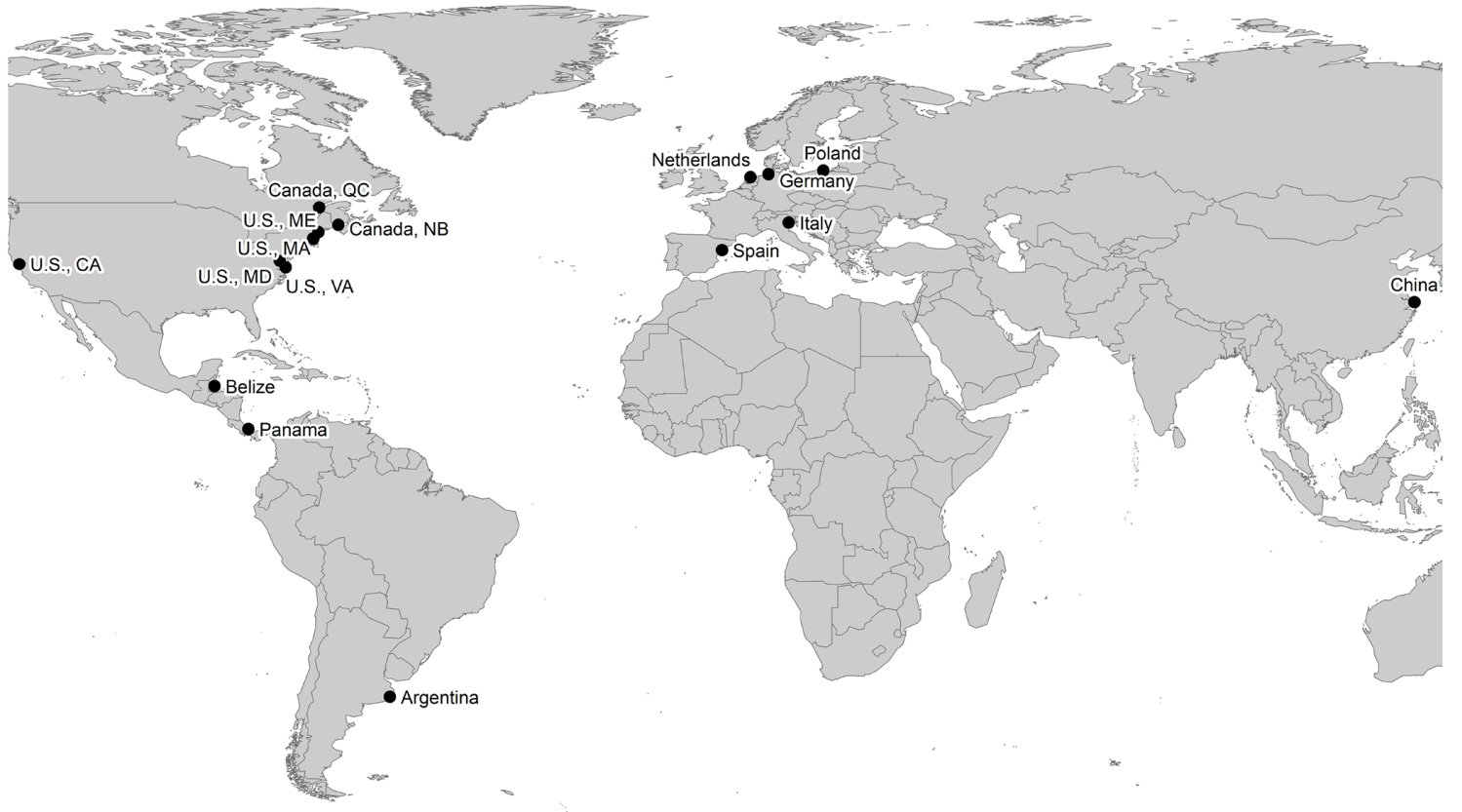

Figure 1. Overview map of study regions. Notes: see Table 1 for region and site details.

spect to SLR-driven increases in flooding frequency - the relevance of nutrient delivery through floodwater for the early stages of OM decomposition in tidal wetlands.

\section{Methods}

\subsection{Study sites and experimental design}

The worldwide survey was conducted during the 2015 growing season and included a total of 30 tidal-wetland sites. Sites were partly co-located within larger coastal and estuarine regions (Fig. 1, Table 1). A total of 11 sites were situated along the European coasts of the North Sea, the Mediterranean, and the Baltic Sea; 13 sites were located along the east and west coasts of North America, including the St. Lawrence estuary, Bay of Fundy, Chesapeake Bay, and San Francisco Bay; and 4 mangrove sites were situated along the Caribbean coast of Central America in Belize and Panama. Additionally, one Chinese site (Yangtze Estuary) and one Argentinian site were included in our study. A total of 16 of the sites were salt marshes, 10 were tidal freshwater and brackish sites, and 4 sites were mangroves. In 21 sites, we compared high and low elevated zones, which were characterized by distinct plant-species compositions (i.e., different communities in high vs. mid vs. low marshes) or by different stature of mangroves (i.e., dwarf vs. fringe phenotypes). We used relative elevation (i.e., high vs. low elevated zone) as a sitespecific proxy for relative sea level. By doing so, we did not capture the actual variability in the tidal inundation regime across our study sites as these vary in absolute elevation and in elevation relative to mean high water. Finally, we included the long-term experimental site of the TIDE project in Massachusetts, USA, to assess effects of nutrient enrichment on litter-decomposition rate and stabilization. Through nitrate additions to the incoming tides on at least 120 days per year, nutrient-enriched areas at the TIDE project site receive floodwater with $10-15$ fold increased nitrogen $(\mathrm{N})$ concentrations compared to reference areas since 2004. From 2004 to 2010 also phosphate was added to the floodwater; however, this has been discontinued because creek water $\mathrm{P}$ concentrations are high enough to prevent secondary $\mathrm{P}$ limitation through $\mathrm{N}$ enrichment (details in Deegan et al., 2012; Johnson et al., 2016).

Decomposition rate and stabilization were measured by deploying tea bags in 10 points per zone (or treatment) within a site $(n=10)$. Spacing between replicates within a zone (or treatment) was $\geq 2 \mathrm{~m}$. However, as sites differed considerably in their areal extent, the distribution and thus spacing between points had to be adjusted to be representative for the given system. Air temperature for the period of deployment was measured at the site, or temperature data was obtained from the online service of AccuWeather (http://accuweather. com, last access: 25 December 2016) for locations within a distance of $15 \mathrm{~km}$ to the site for most sites, but not further than $60 \mathrm{~km}$ for some remote sites. It needs to be noted here that top-soil temperature would differ from air temperature depending on factors such as canopy shading or tidal regime and water temperature. As a consequence, air temperature can only approximate the temperature conditions of the actual decomposition environment (Fig. S2 in the Supplement). 
Table 1. Overview of study regions, site names, and site properties. Sites in which tea bags were deployed in zones of different elevation and flooding frequency are marked $(\times)$. Different salinity classes are indicated as "S" (salt water), "B" (brackish water), and "F" (fresh water). Tidal amplitude (Ampl.) is given in meters.

\begin{tabular}{|c|c|c|c|c|c|c|c|}
\hline Region & Site name & Zonation & Salinity & Ampl. & Ecosystem & Soil $^{\mathrm{c}}$ & Contacts ${ }^{\text {site ref. }}$ \\
\hline \multicolumn{8}{|l|}{ Europe } \\
\hline \multirow[t]{3}{*}{ Germany, Wadden Sea } & Dieksanderkoog & $x$ & $\mathrm{~S}$ & 3.0 & marsh & mineral & Mueller ${ }^{1}$ \\
\hline & Sönke-Nissen-Koog & $x$ & S & 3.4 & marsh & mineral & Mueller $^{1}$ \\
\hline & Spiekeroog & $x$ & $S$ & 2.0 & marsh & mineral & Dinter $^{2}$ \\
\hline \multirow[t]{3}{*}{ The Netherlands, Wadden Sea } & Ameland & $x$ & S & 2.3 & marsh & mineral & de Groot $^{3}$ \\
\hline & Noord-Friesland Buitendijks & $x$ & $S$ & 2.3 & marsh & mineral & Esselink $^{4}$ \\
\hline & Schiermonnikoog $\mathrm{b}$ & - & S & 2.3 & marsh & mineral & $\mathrm{Smit}^{5}$ \\
\hline Italy, Venice Lagoon & Venice Lagoon & $x$ & S & 0.5 & marsh & mineral & D'Alpaos 6 \\
\hline \multirow[t]{3}{*}{ Spain, Ebro Delta } & Vilacoto & - & $\mathrm{F}$ & $<0.1$ & marsh & organic & Ibáñez ${ }^{7}$ \\
\hline & Garxal & - & $\mathrm{B}$ & 0.2 & marsh & organic & Ibáñez ${ }^{7}$ \\
\hline & Alfacs & - & $S$ & 0.2 & marsh & organic & Ibáñez ${ }^{7}$ \\
\hline Poland, Gdańsk Bay & Mechelińskie Łąki ${ }^{b}$ & - & $\mathrm{B}$ & $<0.1$ & marsh & organic & Lazarus \\
\hline \multicolumn{8}{|l|}{ North America } \\
\hline Canada, St. Lawrence Est., QC & Rimouski & $x$ & S & 3.2 & marsh & mineral & Neumeier $^{8}$ \\
\hline Canada, Bay of Fundy, NB & Dipper Harbour & $x$ & $S$ & $>6.0$ & marsh & mineral & Chmura $^{9}$ \\
\hline \multirow[t]{3}{*}{ United States, Casco Bay, ME } & Long Marsh, north of inlet & - & $S$ & 1.4 & marsh & organic & Johnson ${ }^{10}$ \\
\hline & Long Marsh, south of inlet & - & B & 1.4 & marsh & organic & Johnson ${ }^{10}$ \\
\hline & Long Marsh, south of Narrows & - & $\mathrm{F}$ & 1.4 & marsh & organic & Johnson ${ }^{10}$ \\
\hline \multirow[t]{2}{*}{ United States, Plum Island Sound, MA } & Laws Point & $x$ & S & 2.9 & marsh & organic & Mozdzer $^{11}$ \\
\hline & TIDE project ${ }^{\mathrm{a}}$ & $x$ & S & 2.9 & marsh & organic & Mozdzer $^{12}$ \\
\hline \multirow[t]{2}{*}{ United States, Chesapeake Bay, MD } & Patuxent River & $x$ & $\mathrm{~F}$ & 0.7 & marsh & organic & Baldwin $^{13}$ \\
\hline & Rhode River & $x$ & B & 0.2 & marsh & organic & Schile-Beers ${ }^{14}$ \\
\hline United States, Eastern Shore of VA & Wachapreague & $x$ & $S$ & 0.6 & marsh & mineral & Schile-Beers \\
\hline \multirow[t]{3}{*}{ United States, San Francisco Bay, CA } & Coon Island & $x$ & S & 0.7 & marsh & mineral & Schile-Beers ${ }^{15}$ \\
\hline & Rush Ranch & $x$ & B & 0.7 & marsh & mineral & Schile-Beers ${ }^{15}$ \\
\hline & China Camp & - & S & 0.7 & marsh & mineral & Schile-Beers ${ }^{15}$ \\
\hline \multicolumn{8}{|l|}{ Central America } \\
\hline Belize, Caribbean coast & Twin Cays & $x$ & $\mathrm{~S}$ & 0.2 & mangrove & organic & Schile-Beers ${ }^{16}$ \\
\hline \multirow[t]{3}{*}{ Panama, Caribbean coast, Bocas del Toro } & Isla Solarte & $x$ & $S$ & 0.3 & mangrove & organic & Schile-Beers ${ }^{17}$ \\
\hline & Isla Cristóbal & $x$ & S & 0.3 & mangrove & organic & Schile-Beers ${ }^{17}$ \\
\hline & Isla Popa & $\times$ & $\mathrm{S}$ & 0.3 & mangrove & organic & Schile-Beers ${ }^{17}$ \\
\hline \multicolumn{8}{|l|}{ South America } \\
\hline Argentina, Mar Chiquita Lagoon & Mar Chiquita ${ }^{b}$ & $x$ & $\mathrm{~B}$ & 0.8 & marsh & mineral & Montemayor $^{18}$ \\
\hline \multicolumn{8}{|l|}{ Asia } \\
\hline China, Yangtze Estuary & Dongtan & $x$ & S & 2.5 & marsh & mineral & $\mathrm{Wu}^{19}$ \\
\hline
\end{tabular}

Notes: ${ }^{\mathrm{a}}$ additional fertilization treatment was included, compare reference $12 ;{ }^{\mathrm{b}}$ low retrieval rates of paired bags only allowed for calculation of site or zone averages ${ }^{\mathrm{c}}$ If unclear, soil type was judged as mineral at organic matter contents $<35 \%$ (Soil Survey Staff, 2014).

Site references: ${ }^{1}$ Nolte et al. (2013), ${ }^{2}$ Flemming and Davis (1994), ${ }^{3}$ Dijkema et al. (2010), ${ }^{4}$ Chang et al. (2016), ${ }^{5}$ Howison et al. (2015), ${ }^{6}$ Roner et al. (2016), ${ }^{7}$ Benito et al. (2014), ${ }^{8}$ Neumeier and Cheng (2015), ${ }^{9}$ Chmura et al. (1997), ${ }^{10}$ Craig (2015), ${ }^{11}$ Morris et al. (2013), ${ }^{12}$ Deegan et al. (2012), ${ }^{13}$ Neff et al. (2009), ${ }^{14}$ Langley and Megonigal (2010), ${ }^{15}$ Vasey et al. (2012), ${ }^{16}$ McKee et

al. (2007), ${ }^{17}$ Lovelock et al. (2005), ${ }^{18}$ Isacch et al. (2006), ${ }^{19}$ Yang et al. (2017)

\subsection{Decomposition-rate and stabilization measurements}

Decomposition rate $(k)$ and stabilization $(S)$ were assessed following the TBI protocol (Keuskamp et al., 2013). The TBI approach can be considered as a simplified litter-bag approach, allowing a time- and cost-efficient characterization of the decomposition environment, because $k$ and $S$ can be estimated without repeated sampling of the decomposing material as in conventional approaches. This implies the assumptions that (1) $S$ is equal for the two types of material used in the approach and (2) that decomposition of nonhydrolyzable materials during the 3 months of deployment is negligible. We refer the reader to Keuskamp et al. (2013) for further detail and validity assessments of assumptions.

At each measuring point, two nylon tea bags $(200 \mu \mathrm{m}$ mesh size), one containing green tea (EAN: 8722700 055525; Lipton, Unilever, UK) and one containing rooibos (8 722700 188438, Lipton, Unilever, UK), were deployed as pairs in $\sim 8 \mathrm{~cm}$ soil depth, separated by $\sim 5 \mathrm{~cm}$. The initial weight 
of the contents was determined by subtracting the mean weight of 10 empty bags (bag + string + label) from the weight of the intact tea bag prior to deployment (content + bag + string + label). The tea bags were retrieved after an incubation time of $92 \pm 6(\mathrm{SD})$ days, with three sites having an incubation period $>100$ days and one site $<80$ days. Upon retrieval, tea bags were opened, and tea materials were carefully separated from fine roots and soil, dried for $48 \mathrm{~h}$ at $70^{\circ} \mathrm{C}$, and weighed.

Calculations for $k$ and $S$ followed Keuskamp et al. (2013):

$W_{\mathrm{r}}(t)=a_{\mathrm{r}} e^{-k t}+\left(1-a_{\mathrm{r}}\right)$,

$S=1-a_{\mathrm{g}} / H_{\mathrm{g}}$,

$a_{\mathrm{r}}=H_{\mathrm{r}}(1-S)$.

$W_{\mathrm{r}}(t)$ describes the substrate weight of rooibos after incubation time ( $t$ in days), $a_{\mathrm{r}}$ is the labile and $1-a_{\mathrm{r}}$ is the recalcitrant fraction of the substrate, and $k$ is the decomposition rate constant. $S$ describes the stabilization factor, $a_{\mathrm{g}}$ the decomposable fraction of green tea (based on the mass loss during incubation), and $H_{\mathrm{g}}$ the hydrolyzable fraction of green tea. The decomposable fraction of rooibos tea is calculated in Eq. (3) based on its hydrolyzable fraction $\left(H_{\mathrm{r}}\right)$ and the stabilization factor $S$. With $W_{\mathrm{r}}(t)$ and $a_{\mathrm{r}}$ known, $k$ is calculated using Eq. (1).

In accordance with Keuskamp et al. (2013), extractions for determination of the hydrolyzable fractions of green and rooibos tea followed Ryan et al. (1990). However, instead of using Ryan's "forest products protocol" we conducted the alternative "forage fiber protocol" for the determination of the hydrolyzable fraction. Briefly, $1 \mathrm{~g}$ of dried tea material $\left(70^{\circ} \mathrm{C}\right.$ for $24 \mathrm{~h}$ ) was boiled in cetyltrimethylammonium bro-

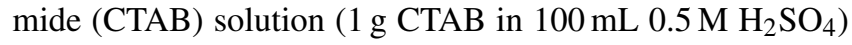
for $1 \mathrm{~h}$ (Brinkmann et al., 2002; Ryan et al., 1990). The extract was filtered through a $16-40 \mu \mathrm{m}$ sinter filter crucible (Duran, Wertheim, Germany) using a water-jet vacuum pump and washed with $150 \mathrm{~mL}$ of hot water followed by addition of acetone until no further de-coloration occurred (Brinkmann et al., 2002). The remaining material was left in the sinter, dried for $12 \mathrm{~h}$ at $70^{\circ} \mathrm{C}$, cooled in a desiccator, and weighed. $20 \mathrm{~mL}$ of $72 \% \mathrm{H}_{2} \mathrm{SO}_{4}$ was added to the sinter and filtered off after an incubation of $3 \mathrm{~h}$, followed by washing with hot water to remove remaining acid. The sinter was dried at $70^{\circ} \mathrm{C}$ for $12 \mathrm{~h}$, cooled in a desiccator, and weighed to determine the non-hydrolyzable fraction. Finally, the sinter containing the remaining sample was ignited at $450{ }^{\circ} \mathrm{C}$ for $3 \mathrm{~h}$ in order to determine the ash content of the material.

In addition to the determination of the hydrolyzable fraction, we measured total $\mathrm{C}$ and $\mathrm{N}$ contents of the tea material using an elemental analyzer (EURO-EA 3000, Euro Vector, Pavia, Italy). The hydrolyzable fraction of both green and rooibos tea was higher than reported in Keuskamp et al. (2013) (Table S1 in the Supplement). However, the determined $\mathrm{C}$ and $\mathrm{N}$ contents of the tea materials are in agreement with those reported in Keuskamp et al. (2013) (Table S1).
Therefore, deviations from the hydrolyzable fraction as reported previously are likely due to the less conservative extraction assessment in the present study and not due to actual changes in the quality of the materials.

\subsection{Data mining}

Relationships between single parameters and litter decomposition are often not linear. Instead, critical thresholds seem to exist at which a certain predictor (e.g., mean annual temperature) becomes influential (Prescott, 2010; Rothwell et al., 2008). In the first step of data mining, we therefore used classification and regression tree analysis (CART) to identify potential thresholds and important predictors for $k$ and $S$ (Fig. S1 in the Supplement). Data mining was conducted using STATISTICA 10 (StatSoft Inc., Tulsa, OK, USA).

\subsection{Statistical analyses}

To test for effects of temperature on $k$ and $S$, Spearman rank correlations were conducted using site means $(n=30)$. As we did not expect temperature to be independent of other parameters in this observational study, we constructed a Spearman correlation matrix including the parameters temperature, latitude, tidal amplitude, salinity class, $k$, and $S$. Additionally, we tested for differences in these parameters between marshes and mangroves and sites with mineral and organic soils, using Mann-Whitney $U$ tests (Table 2). Curve fitting was used to further explore relationships between temperature, $k$, and $S$, and regression models with the lowest standard error of estimate and highest $R^{2}$ are displayed in Figs. 2 and 3.

To test for effects of relative elevation (as proxy for relative sea level) on $k$ and $S$, two-tailed paired $t$ tests were conducted. Mean values of high and low elevated zones of the 21 sites where tea bags were deployed in both high and low elevation zones were used $(n=21)$. The absence of outliers and normal distribution of the difference in the independent variable (as assessed visually) assured robustness of paired $t$ tests. To assess the consistency of potential effects of relative elevation on $k$ and $S$, one-way ANOVAs were used in each site separately (replication was sufficient in 20 sites). Normal distribution of residuals was assessed visually, Levene's test was used to test for homogeneity of variance, and data were log-transformed if assumptions were not met. Mann-Whitney $U$ tests were conducted as a non-parametric alternative when log-transformed data did not meet ANOVA assumptions (Table S2).

We tested for effects of nutrient enrichment on $k$ and $S$ in the data from the TIDE project site (Massachusetts, USA) using two-way ANOVA with enrichment treatment and marsh zone as predictors. When Levene's test indicated heterogeneous variance (true for $k$ ), data were log-transformed, which stabilized variance. Normal distribution of residuals was assessed visually. 

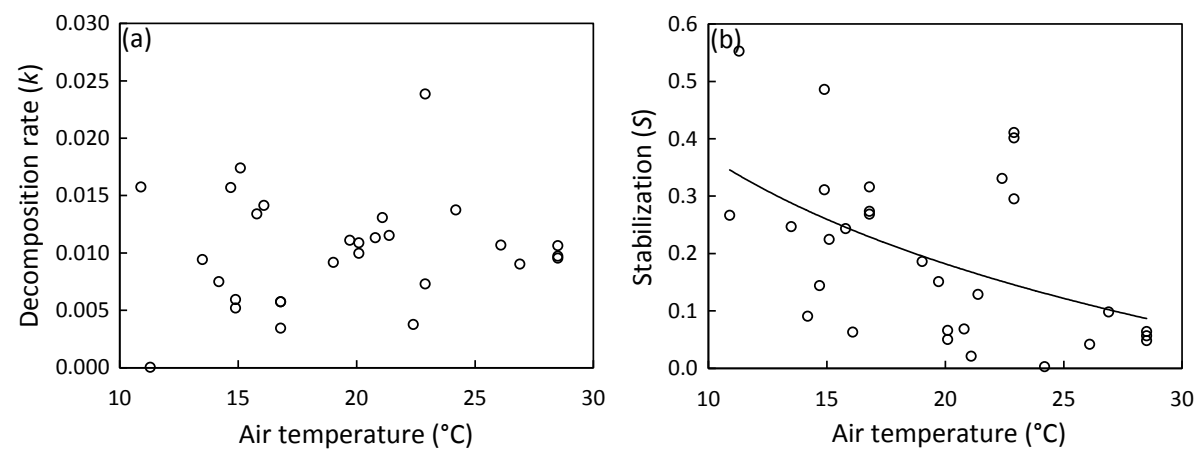

Figure 2. Site means of decomposition rate (a) and stabilization (b) versus mean air temperature during deployment period. Regression line illustrates the significant relationship between temperature and stabilization (Table 2); the regression model with the lowest standard error of estimate (SEE) and highest $R^{2}$ is shown: $y=-0.27 \ln (x)+0.99 ; R^{2}=0.239$; $\mathrm{SEE}=0.131$. Excluding Mediterranean sites $\left(21.9-23.6^{\circ} \mathrm{C}\right.$; $n=4$ ) from the regression yields the following: $y=-0.344 \ln (x)+1.233 ; R^{2}=0.510 ; \mathrm{SEE}=0.101$.

Lastly, in order to assess the applicability of the TBI approach in tidal wetlands, we separately investigated the temperature response of $k$ and $S$ for the 10 sites situated along the North American Atlantic coast (Fig. 3). Previous studies have shown clear temperature (or latitudinal) effects on decomposition and microbial activity along this well-studied transect (Kirwan et al., 2014; Mozdzer et al., 2014), allowing us to compare the TBI approach with other methods. Regionalscale transects with sufficient temperature range along other coastlines could not be identified (Fig. 1; Table 1). Statistical analyses were conducted using STATISTICA 10 (StatSoft Inc., Tulsa, OK, USA).

\section{Results}

\subsection{Temperature effects}

We found no relationship between temperature and $k$ across study sites (Fig. 2a; Table 2). Also, CART revealed temperature only as a subordinate splitting variable for $k$. Specifically, temperature seems to positively affect $k$ in mesotidal systems only (amplitude $>2.1 \mathrm{~m}$ ) with sites $\geq 14.5^{\circ} \mathrm{C}$ during deployment supporting higher rates of decomposition than sites characterized by lower temperatures. However, this apparent temperature effect was inconsistent within the group of observations with tidal amplitude $>2.1 \mathrm{~m}$ (Fig. S1a). In contrast to the results of the global-scale assessment, $k$ was strongly and positively related with temperature across the 10 sites situated along the North American Atlantic coast, with temperature explaining approx. $70 \%$ of variability in $k$ (Fig. 3a).

Stabilization was strongly affected by temperature (Fig. 2b; Table 2). The significant negative correlation between $S$ and temperature agrees well with the CART. However, CART also identified a narrow temperature range (21.9-23.6 ${ }^{\circ} \mathrm{C}$ ) in which increasing temperature led to higher stabilization (Fig. S1b; node 11). This group of observations diverging from the general pattern is also clearly visible in Fig. $2 b$ and represents the four Mediterranean sites (Ebro Delta and Venice Lagoon) of our survey. The positive relationship between temperature and $S$ was even clearer when focusing on the 10 sites along the North American Atlantic coast, with temperature explaining $>85 \%$ of variability in $S$ (Fig. 3b).

Temperature was highly correlated with latitude and tidal amplitude, and temperature was not independent of soil type (mineral or organic) and ecosystem type (marsh or mangrove) (Table 2 ). The effect of latitude was similarly pronounced as the temperature effect on $S$ - and consequently - effects of these two parameters on $S$ cannot be separated (Table 2). By contrast, tidal amplitude and soil type did not significantly affect $S$, and the difference in $S$ between mangroves and marshes was only marginally significant (Table 2). These findings suggest that the presented temperature effect on $S$ occurs to be mainly independent of tidal amplitude and soil type.

\subsection{Effects of relative sea level and nutrient enrichment}

Paired comparisons of high vs. low elevated zones indicate no consistent effect of relative sea level on $k$ across sites ( $p>0.1$; Fig. 4a), whereas $S$ was significantly reduced by $29 \%$ in low compared to high elevated zones $(p<0.01$; Fig. $4 b)$. Testing for effects of relative sea level within each site separately revealed that $S$ is significantly reduced by 28 $87 \%$ in the lower elevated zone in 14 of 20 sites, whereas a significant increase of $S$ in low vs. high elevated zones was found in none of the 20 sites (Table S2). This finding demonstrates the consistency of the sea-level effect on $S$ irrespective of ecosystem type (marsh or mangrove), soil type (mineral or organic), and site salinity (brackish or salt water). In nine of the sites, we also found a significant effect of relative sea level on $k$. However, in six sites $k$ was significantly higher in low vs. high zones, and in three sites $k$ was significantly lower in low vs. high zones. The direction of effects on $k$ 


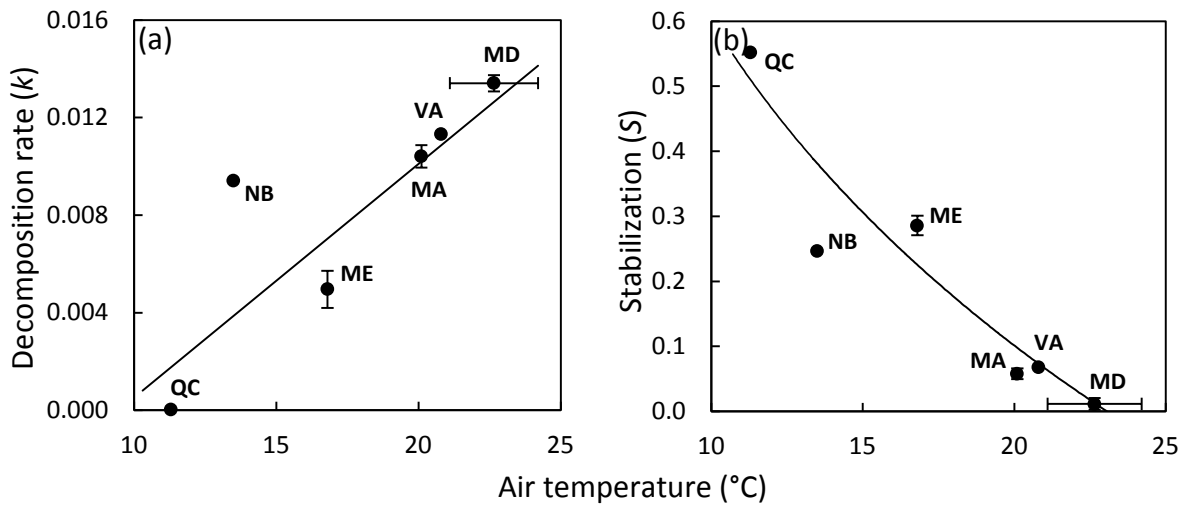

Figure 3. Site means of decomposition rate (a) and stabilization (b) versus mean air temperature of the deployment period shown for the 10 sites situated along the latitudinal gradient of the North American Atlantic coast; state abbreviations are shown (compare Table 1). Regression lines illustrate significant relationships; regression models with the lowest standard error of estimate (SEE) and highest $R^{2}$ are shown. Decomposition rate: $y=0.001 x-0.0091 ; R^{2}=0.692 ;$ SEE $=0.003$. Stabilization: $y=-0.712 \ln (x)+2.2331 ; R^{2}=0.860$; $\mathrm{SEE}=0.070$

Table 2. Spearman rank coefficients between the variables temperature, latitude, tidal amplitude, salinity class, $k$, and $S$ (coefficients are bold typed at $p \leq 0.05)$ and comparisons of temperature $\left({ }^{\circ} \mathrm{C}\right)$, latitude $\left({ }^{\circ}\right)$, amplitude $(\mathrm{m}), k$, and $S$ between ecosystem types (mangrove vs. marsh) and soil types (mineral vs. organic) shown as site means \pm SE, $n=30$. Asterisks show results of Mann-Whitney $U$ tests and denote significant differences as follows: $p \leq 0.1=, p \leq 0.05=*, p \leq 0.01=* *$, not significant $=\mathrm{ns}$.

\begin{tabular}{|c|c|c|c|c|c|c|}
\hline & Temperature & Latitude & Amplitude & Salinity & $S$ & $k$ \\
\hline \multicolumn{7}{|c|}{ Spearman rank correlations } \\
\hline Temperature & & -0.78 & -0.68 & -0.09 & -0.44 & 0.02 \\
\hline Latitude & -0.78 & & 0.49 & 0.05 & 0.43 & 0.06 \\
\hline Amplitude & -0.68 & 0.49 & & 0.40 & 0.01 & 0.00 \\
\hline Salinity & -0.09 & 0.05 & 0.40 & & -0.13 & -0.08 \\
\hline$S$ & -0.44 & 0.43 & 0.01 & -0.13 & & -0.51 \\
\hline$k$ & 0.02 & 0.06 & 0.00 & -0.08 & -0.51 & \\
\hline \multicolumn{7}{|c|}{ Group means $\pm \mathrm{SE}$} \\
\hline Soil type & $* *$ & ns & $* *$ & & ns & ns \\
\hline Mineral & $17.0 \pm 1.1$ & $45.5 \pm 2.1$ & $2.3 \pm 0.6$ & & $0.22 \pm 0.04$ & $0.010 \pm 0.001$ \\
\hline Organic & $22.2 \pm 1.2$ & $34.5 \pm 3.9$ & $0.8 \pm 0.3$ & & $0.17 \pm 0.04$ & $0.010 \pm 0.001$ \\
\hline Ecosystem & $* *$ & $* *$ & $*$ & & $\cdot$ & $\mathrm{ns}$ \\
\hline Marsh & $18.3 \pm 0.8$ & $44.4 \pm 1.3$ & $1.7 \pm 0.4$ & & $0.22 \pm 0.03$ & $0.010 \pm 0.001$ \\
\hline Mangrove & $28.1 \pm 0.4$ & $11.4 \pm 2.0$ & $0.3 \pm 0.0$ & & $0.07 \pm 0.01$ & $0.010 \pm 0.000$ \\
\hline
\end{tabular}

seems to be independent of ecosystem type, soil type, and site salinity (Table S2).

The nutrient enrichment treatment at the TIDE project site decreased $S$ by $72 \%$ in the high marsh (Fig. 4 d). $S$ in the low marsh was similarly low as in the enriched high marsh and not further reduced by nutrient enrichment (Fig. 4d). In contrast, $k$ was not responsive to the nutrient enrichment treatment in either low or high marsh (Fig. 4c).

\subsection{Other factors influencing decomposition rate and stabilization}

CART revealed tidal amplitude as an important predictor for $k$. However, this result needs to be considered cautiously because splits based on tidal amplitude suggest mixed effects (Fig. S1a). Accordingly, no significant relationship existed between tidal amplitude and $k$ across sites (Table 2). Soil type (mineral or organic) and ecosystem type (marsh or mangrove) did not affect $k$ and $S$ across sites (Table 2). We found no significant relationship between salinity class and $k$ or $S$ (Table 2). Also, CART did not reveal salinity class as an important factor for $k$ and $S$. 

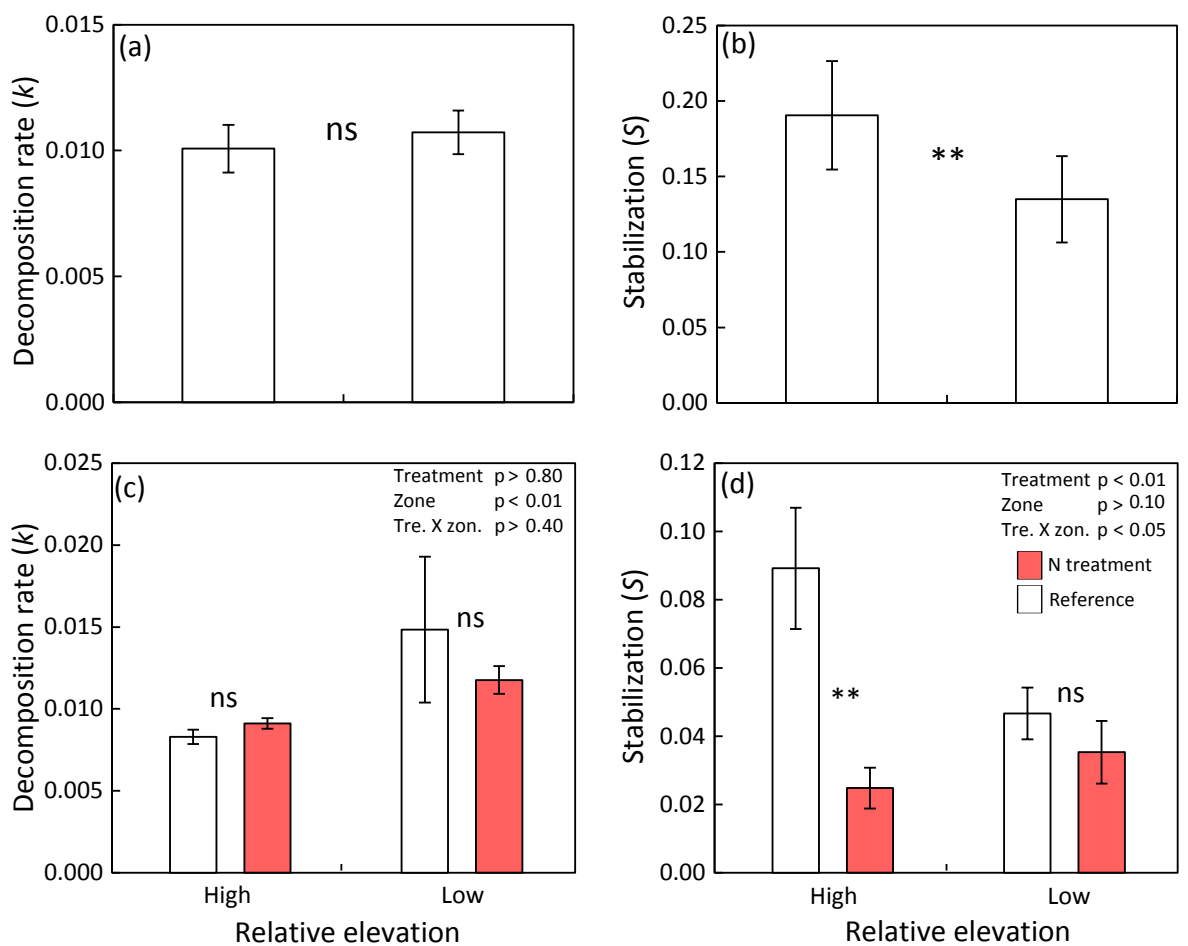

Figure 4. (a) Decomposition rate and (b) stabilization in high and low elevated zones of tidal marsh and mangrove sites ( $n=21$; compare Tables 1, S2). (c) Decomposition rate and (d) stabilization in nutrient-enriched versus reference high marsh (Spartina patens zone) and low marsh (Spartina alterniflora zone) of the TIDE project site at the Plum Island Sound estuary, Massachusetts, USA. Shown are means \pm SE and results of paired $t$ tests $(\mathbf{a}, \mathbf{b})$ and two-way ANOVAs plus Tukey's HSD (honest significant difference) test for pairwise comparisons (c, d): $\mathrm{ns}=$ not significant; $*=p \leq 0.05 ; * *=p \leq 0.01$.

\section{Discussion}

\subsection{Temperature effects on decomposition processes}

A positive relationship between temperature and decomposition rate was found only at the regional scale across the 10 sites along the North American Atlantic coast (Fig. 3a), but not across all sites at the global scale (Fig. 2a). Even though this finding seems surprising in the context of basic biokinetic theory, it is in agreement with findings of Djukic et al. (2018), demonstrating climate effects on the breakdown of the TBI materials across terrestrial ecosystems at the biome scale, but not at the global scale across biomes.

The present study used air temperature as a proxy for topsoil temperature. Thus, the temperature regime of the decomposition environment was only approximated, which certainly would have weakened a significant relationship between temperature and $k$. However, following typical $Q_{10}$ values for biological systems of 2-3 (Davidson and Janssens, 2006), $k$ should have at least doubled over the gradient of $\Delta T>15^{\circ} \mathrm{C}$; yet our data do not even show a tendency of an effect $\left(r_{\mathrm{s}}=0.02\right.$; Table 2$)$. We therefore propose that other parameters exerted overriding influence on $k$, mainly masking temperature effects, and have not been captured by our study design. This notion is in line with the fact that studies conducted at single-marsh to regional scales report equivocal results on the temperature response of $k$, ranging from no or moderate (Charles and Dukes, 2009; Janousek et al., 2017; Kirwan et al., 2014) to strong seasonally driven temperature effects with a $Q_{10}>3.4$ as found within a single site (Kirwan and Blum, 2011). For instance, large differences in site elevation and hydrology could have induced high variability in $k$ across sites and masked potential temperature effects. Indeed, we demonstrate significant but mixed effects of relative sea level on $k$ for some sites (Table S2); however, we do not have sufficient data on actual site elevation or hydrology to control for these factors as covariates affecting the temperature effect on $k$. Likewise, we do not have data on nutrient availability, plant productivity, or various anthropogenic impacts that could have exerted strong control over decomposition processes in the studied sites (Deegan et al., 2012; Keuskamp et al., 2015b; Macreadie et al., 2017; Mueller et al., 2016).

In contrast to the missing effect of temperature on $k, \mathrm{OM}$ stabilization was strongly affected. Overall, $S$ decreased by $75 \%$ over our temperature gradient from 10.9 to $28.5^{\circ} \mathrm{C}$ (Fig. 2b). Thus, we demonstrate a considerable temperature effect on the initial steps of biomass decomposition in tidal wetlands. However, as also demonstrated for $k$, the tempera- 
ture effect on $S$ was much clearer at the regional scale when focusing on the sites along the North American Atlantic coast (Fig. 3b), suggesting high variability in $S$ across regions irrespective of the temperature regime. In accordance, we also demonstrate a clear divergence of the four Mediterranean sites from the regression model (Fig. 2b), which could be related to differences in precipitation or nutrient availability across study regions. Future experimental work is therefore required in order to further assess the effects of temperature on OM stabilization and to separate temperature from latitudinal and other interacting effects (e.g., as outlined above for $k$ ) that are difficult to control for in observational studies.

The temperature effect on the initial steps of biomass decomposition we identified in the present study is not driven by changes in decomposition rate per se, but by changes in the transformation of fresh and rapidly decomposable organic matter into stable compounds. This could have important implications for carbon sequestration (e.g., Cotrufo et al., 2013). In their global-scale assessment, Chmura et al. (2003) indeed report a negative relationship of soil organic $\mathrm{C}$ density and mean annual temperature within both salt marshes and mangroves. Chmura and colleagues hypothesized stimulated microbial decomposition at higher temperatures to be the responsible driver of this relationship. Plant production and thus OM input is known to increase with latitude and temperature in tidal wetlands (Baldwin et al., 2014; Charles and Dukes, 2009; Gedan and Bertness, 2009; Kirwan et al., 2009), but this increase seems to be more than compensated for by higher microbial decomposition. Working at the same spatial scale as Chmura et al. (2003), our study supports this hypothesis and provides mechanistic insight into the temperature control of OM decomposition as a potential driver of carbon sequestration in tidal wetlands.

\subsection{Relative-sea-level effects on decomposition processes}

Flooding and thus progressively lower oxygen availability in soil is supposed to be a strong suppressor of decomposition (Davidson and Janssens, 2006). In tidal wetlands, differences in flooding frequency along elevational gradients often induce sharp gradients in oxygen availability and redox conditions (Davy et al., 2011; Kirwan et al., 2013; Langley et al., 2013), with potentially strong influence on OM decomposition and carbon cycling. However, the effect of redox conditions on OM breakdown is determined by the chemical quality of the decomposing material: decomposition of aged or recalcitrant OM can indeed be slower and incomplete in the absence of oxygen, whereas the breakdown of fresh and labile OM can be largely unaffected by oxygen availability (Benner et al., 1984; Kristensen et al., 1995). Thus, also decomposition rate and stabilization of labile, hydrolyzable OM, as assessed in the present study, is not necessarily affected by redox conditions. Here, we demonstrate that $k$ is not reduced in low (more frequently flooded) vs. high elevated (less frequently flooded) zones of tidal wetlands (Fig. 4a). This finding is in accordance with an increasing number of studies demonstrating negligible direct effects of sea level on decomposition rate in tidal-wetland soils (Janousek et al., 2017; Kirwan et al., 2013; Mueller et al., 2016). Furthermore, we show that $S$ is strongly reduced in low vs. high elevation zones, suggesting that the conversion of recent OM inputs to stable compounds is in fact lower in more flooded zones of tidal wetlands. As the stabilization of labile OM inputs is a major driver of SOM formation (Cotrufo et al., 2013, 2015; Haddix et al., 2016), one important implication of this finding is that accelerated SLR yields the potential to decrease the carbon-sequestration potential of tidal wetlands.

The mechanism by which $S$ is decreased in the more flooded zones of the present study is unknown. Because we did not observe consistent salinity effects on $S$ and $k$ in our data, we do not suppose that regular exposure of litter to salt water explains the unexpected finding. Likewise, soil temperature was not consistently affected by relative elevation across sites $(p>0.3$; paired $t$ test based on data shown in Fig. S2). Instead, we argue that more favorable soil moisture conditions in low vs. high elevated zones could have decreased OM stabilization if higher flooding frequencies did not induce redox conditions low enough to suppress microbial activity in the top soil. In support of this, floodingfrequency-induced changes in moisture conditions have been reported as the primary driver of surface litter breakdown, leading to more than 4-fold increased litter mass loss in lowvs. high-marsh zones of a New Jersey salt marsh (Halupa and Howes, 1995). Additionally, greater nutrient availability and less nutrient-limited microbial communities in more frequently flooded zones could have contributed to this effect (Deegan et al., 2012; Kirwan et al., 2013). Strong effects of both high-quality marine-derived $\mathrm{OM}$ and nutrient amendments on microbial structure and activity have been reported (Deegan et al., 2012; Kearns et al., 2016; Keuskamp et al., 2015a; Mueller et al., 2017), suggesting that regular marine $\mathrm{OM}$ and nutrient inputs in more frequently flooded zones can positively affect decomposition (see further discussed below in Sect. 4.3).

\subsection{Nutrient enrichment reduces stabilization - insights from the TIDE project}

In addition to our global survey of early-stage decomposition processes in tidal wetlands, we included the long-term ecological research site of the TIDE project in Massachusetts, USA, to experimentally assess both the effects of coastal eutrophication and the relevance of nutrient delivery through floodwater for OM decomposition in tidal wetlands. Important for our argument that decomposition may be favored by higher nutrient availability in low elevated, more frequently flooded zones, we observed a strong reduction $(>70 \%)$ of $S$ by nutrient enrichment in the high marsh. Additionally, 
$S$ in the low marsh was low as in the fertilized high marsh and not further reduced by fertilization (Fig. 4d). Johnson et al. (2016) demonstrate that nutrient-enriched high-marsh plots of the TIDE project receive $19 \pm 2 \mathrm{~g} \mathrm{~N} \mathrm{~m}^{-2} \mathrm{yr}^{1}$, approximately 10 times the $\mathrm{N}$ load of reference high-marsh plots $\left(2 \pm 1 \mathrm{~g} \mathrm{~N} \mathrm{~m}^{-2} \mathrm{yr}^{-1}\right.$; mean $\left.\pm \mathrm{SE}\right)$, thus explaining the strong treatment effect observed in the high marsh. In accordance with low stabilization in the reference low marsh, which is as equally low as the nutrient-enriched high marsh, reference plots of the low marsh receive $16 \pm 4 \mathrm{~g} \mathrm{~N} \mathrm{~m}^{-2} \mathrm{yr}^{1}$, the same high $\mathrm{N}$ load as the enriched high-marsh plots. Surprisingly, however, $\mathrm{N}$ loads of $171 \pm 19 \mathrm{~g} \mathrm{~N} \mathrm{~m}^{-2} \mathrm{yr}^{1}$ in the enriched lowmarsh plots do not result in additional reduction of $S$ compared to the reference low marsh (Fig. 4d). These findings suggest that microbial communities of the high marsh are $\mathrm{N}$ limited and that $\mathrm{N}$ additions to a certain level can stimulate early OM decomposition and thus reduce stabilization. The missing effect of $\mathrm{N}$ loads exceeding $16 \mathrm{~g} \mathrm{~m}^{-2} \mathrm{yr}^{1}$ on stabilization in the low marsh indicates that microbial communities are less $\mathrm{N}$ limited due to the naturally greater nutrient availability. The findings of the TIDE project therefore support our concept that higher nutrient availability and less nutrient-limited microbial communities in more frequently flooded zones could have contributed to the observed reduction of OM stabilization in low vs. high elevated zones of tidal wetlands in our global assessment.

Although our conclusions on effects of nutrient enrichment on OM decomposition are based on the findings of a single field experiment only, our study adds to a growing number of reports illustrating the impact of coastal eutrophication on tidal-wetland C cycling (Deegan et al., 2012; Keuskamp et al., 2015b; Kirwan and Megonigal, 2013; Morris and Bradley, 1999). At the same time, however, we highlight the need to improve our understanding of coastal eutrophication in interaction with other global changes, particularly accelerated SLR and concomitant changes in flooding frequency, on the cycling of both labile and refractory $\mathrm{C}$ pools in order to predict future stability of tidal wetlands.

\subsection{The Tea Bag Index - methodological considerations}

Interpretation of results obtained from standardized approaches like the present needs to be made cautiously because OM quality (i.e., its chemical composition) is a key parameter affecting its decomposition. As the quality of the TBI materials differ from that of wetland plant litters, and likely even more from the quality of the imported allochthonous OM (Khan et al., 2015), we did not expect to capture actual rates of early-stage OM breakdown in this study. Instead, we used the TBI to characterize the decomposition environment by obtaining a measure for the potential to decompose and stabilize the deployed standardized material. Standardized approaches like this, or also the cotton-strip assay (e.g., Latter and Walton, 1988), are useful to separate the effects of environmental factors other than OM quality on decomposition processes and to assess their relative importance. Otherwise, complex interaction effects of the abiotic environment and OM quality make it difficult to predict the relevance of certain environmental factors for decomposition processes, potentially masking the effects of important global-change drivers (Prescott, 2010). At the same time, however, the global-change factors considered in the present study are likely to induce changes in the quality of the $\mathrm{OM}$ accumulating in tidal wetlands, for instance through shifts in plant-species composition and plant-tissue quality, that can potentially counterbalance or amplify the effects on decomposition processes suggested here. Future research therefore needs to address OM quality feedbacks on decomposition processes in tidal wetlands in order to gain a more complete understanding of global-change effects on tidal-wetland stability and carbon-sequestration capacity.

Based on the $S$ values obtained from initial calculations using the hydrolyzable fractions suggested by Keuskamp et al. (2013), a large number of observations yielded a negative $S$ (Table S3). $S$ becomes negative when the mass loss from green tea is greater than the predicated maximum loss based on its hydrolyzable fraction. At least two processes could have caused this result: first, our data indicate that redox conditions in the top soil of tidal wetlands are not low enough to hamper decomposition of the hydrolyzable fraction of the TBI materials. As a consequence, high top-soil moisture of tidal wetlands could provide favorable conditions for decomposition, following typical moisture-decomposition relationships as demonstrated for terrestrial ecosystems (e.g., Curiel Yuste et al., 2007). Potentially, moisture conditions and nutrient supply even allow for considerable breakdown of non-hydrolyzable compounds within three months of deployment, such as lignin (Berg and McClaugherty, 2014; Duboc et al., 2014; Feng et al., 2010; Knorr et al., 2005). Second, different protocols to determine the hydrolyzable fraction of plant materials exist and lead to variable results. The hydrolyzable fraction can consequently be over- or underestimated depending on protocol and type of sample material. The use of the slightly higher hydrolyzable fractions we determined for calculations of the TBI parameters effectively eliminated negative $S$ values. In that regard, using the values obtained from the alternative protocol given in Ryan et al. (1990) seemed more reasonable in our study. However, it needs to be stressed here that direction and size of reported effects on $S$ and $k$ in the present study are almost independent of the hydrolyzable fraction used for calculations.

Future research will have to test the applicability of the TBI approach in different ecosystems and test the validity of its assumptions (i.e., $S$ is equal for both types of material used, and mass loss of non-hydrolyzable material is negligible over 3 months of deployment). The results of our regional-scale assessment along the North American Atlantic coast transect are in tight agreement with previously reported results on cellulose breakdown and soil microbial activity along this well-studied transect (Kirwan et al., 2014; 
Mozdzer et al., 2014). We can thereby demonstrate the usefulness of the TBI approach to assess early-stage decomposition in tidal-wetland soils.

\subsection{Implications}

This study addresses the influence of temperature, relative sea level, and coastal eutrophication on the initial transformation of biomass to SOM, and it does not encompass their effects on the existing SOM pool. However, aspects of $S$ and $k$ are key components of many tidal-wetland resiliency models (Schile et al., 2014; Swanson et al., 2014) that have highlighted the critical role of the organic contribution to marsh elevation gain. Although actual rates of $S$ and $k$ cannot be inferred from this study using a standardized approach, our data identify strong negative effects of temperature, relative sea level, and coastal eutrophication on the stabilization of fresh organic inputs to tidal-wetland soils. We argue that these unanticipated combined effects yield the potential to strongly accelerate carbon turnover in tidal wetlands, thus increasing their vulnerability to accelerated SLR, and we highlight the need for experimental studies assessing the extent to which the here identified effects translate into native $\mathrm{OM}$ dynamics.

Data availability. The data used in this work are available at the PANGEA digital data library (Mueller et al., 2018).

Supplement. The supplement related to this article is available online at: https://doi.org/10.5194/bg-15-3189-2018-supplement.

Author contributions. PM, SN, KJ, and LMSB designed the overall study. PM analyzed and interpreted the data. PM wrote the initial version of the manuscript with regular comments and editing provided by LMSB, TJM, and SN. PM, LMSB, TJM, GLC, TD, YK, AVdG, PE, CS, AD'A, CI, ML, UN, BJJ, AHB, SAY, DIM, ZY, and JW designed and conducted the field studies in the respective sites and commented on an earlier version of the manuscript.

Competing interests. The authors declare that they have no conflict of interest.

Acknowledgements. We thank Svenja Reents, Melike Yildiz, Anja Schrader, Detlef Böhm, Cailene Gunn, Marcella Roner, Johan Krol, Marin van Regteren, Jacek Mazur, Ana Genua, Lluís Jornet, David Mateu, Sarah King, Shayne Levoy, and Lyntana Brougham for help with field and lab work. We thank Joost Keuskamp, Judith Sarneel, Catherine Lovelock, and two anonymous reviewers for their valuable comments on our manuscript. The project was partly funded by the Bauer-Hollmann Stiftung and the Rudolf und Helene Glaser Stiftung in the framework of the INTERFACE project. We acknowledge the financial support provided by the International Affairs, Strategy and Partnership office of Universität Hamburg. Support for Thomas J. Mozdzer came from NSF DEB-1354124 and DEB-1719621. This is contribution 25 from the Smithsonian's MarineGEO Network.

Edited by: Gwenaël Abril

Reviewed by: Joost Keuskamp and two anonymous referees

\section{References}

Baldwin, A. H., Jensen, K., and Schönfeldt, M.: Warming increases plant biomass and reduces diversity across continents, latitudes, and species migration scenarios in experimental wetland communities, Glob. Change Biol., 20, 835-850, https://doi.org/10.1111/gcb.12378, 2014.

Barbier, E. B., Hacker, S. D., Kennedy, C., Koch, E., Stier, A. C., and Silliman, B. R.: The value of estuarine and coastal ecosystem services, Ecol. Monogr., 81, 169-193, https://doi.org/10.1890/10-1510.1, 2011.

Benito, X., Trobajo, R., and Ibáñez, C.: Modelling habitat distribution of Mediterranean coastal wetlands: The Ebro delta as case study, Wetlands, 34, 775-785, https://doi.org/10.1007/s13157014-0541-2, 2014.

Benner, R., Maccubbin, A. E., and Hodson, R. E.: Anaerobic biodegradation of the lignin and polysaccharide components of lignocellulose and synthetic lignin by sediment microflora, Appl. Envir. Microbiol., 47, 998-1004, https://doi.org/10.3354/meps023221, 1984.

Berg, B. and McClaugherty, C.: Plant litter: Decomposition, humus formation, carbon sequestration, 3rd edition, Springer-Verlag, Berlin/Heidelberg, 2014.

Berg, B., Berg, M. P., Bottner, P., Box, E., Breymeyer, A., de Anta, R. C., Couteaux, M., Escudero, A., Gallardo, A., Kratz, W., Madeira, M., Mälkönen, E., McClaugherty, C., Meentemeyer, V., Muñoz, F., Piussi, P., Remacle, J., and de Santo, A. V.: Litter mass loss rates in pine forests of Europe and Eastern United States: some relationships with climate and litter quality, Biogeochemistry, 20, 127-159, https://doi.org/10.1007/BF00000785, 1993.

Brinkmann, K., Blaschke, L., and Polle, A.: Comparison of different methods for lignin determination as a basis for calibration of near-infrared reflectance spectroscopy and implications of lignoproteins, J. Chem. Ecol., 28, 2483-501, 2002.

Castellano, M. J., Mueller, K. E., Olk, D. C., Sawyer, J. E., and Six, J.: Integrating plant litter quality, soil organic matter stabilization, and the carbon saturation concept, Glob. Change Biol., 21, 3200-3209, https://doi.org/10.1111/gcb.12982, 2015.

Chang, E. R., Veeneklaas, R. M., Bakker, J. P., Daniels, P., and Esselink, P.: What factors determined restoration success of a salt marsh ten years after de-embankment?, Appl. Veg. Sci., 19, 6677, https://doi.org/10.1111/avsc.12195, 2016.

Charles, H. and Dukes, J. S.: Effects of warming and altered precipitation on plant and nutrient dynamics of a New England salt marsh, Ecol. Appl., 19, 1758-1773, https://doi.org/10.1890/080172.1, 2009.

Chmura, G., Chase, P., and Bercovitch, J.: Climatic Controls of the Middle Marsh Zone in the Bay of Fundy, Estuaries, 20, 689-699, 1997. 
Chmura, G. L., Anisfeld, S. C., Cahoon, D. R., and Lynch, J. C.: Global carbon sequestration in tidal, saline wetland soils, Global Biogeochem. Cy., 17, 22-1-22-11, https://doi.org/10.1029/2002GB001917, 2003.

Cornelissen, J. H. C., Van Bodegom, P. M., Aerts, R., Callaghan, T. V., Van Logtestijn, R. S. P., Alatalo, J., Stuart Chapin, F., Gerdol, R., Gudmundsson, J., Gwynn-Jones, D., Hartley, A. E., Hik, D. S., Hofgaard, A., Jónsdóttir, I. S., Karlsson, S., Klein, J. A., Laundre, J., Magnusson, B., Michelsen, A., Molau, U., Onipchenko, V. G., Quested, H. M., Sandvik, S. M., Schmidt, I. K., Shaver, G. R., Solheim, B., Soudzilovskaia, N. A., Stenström, A., Tolvanen, A., Totland, Ø., Wada, N., Welker, J. M., Zhao, X., Brancaleoni, L., Brancaleoni, L., De Beus, M. A. H., Cooper, E. J., Dalen, L., Harte, J., Hobbie, S. E., Hoefsloot, G., Jägerbrand, A., Jonasson, S., Lee, J. A., Lindblad, K., Melillo, J. M., Neill, C., Press, M. C., Rozema, J., and Zielke, M.: Global negative vegetation feedback to climate warming responses of leaf litter decomposition rates in cold biomes, Ecol. Lett., 10, 619-627, https://doi.org/10.1111/j.1461-0248.2007.01051.x, 2007.

Cotrufo, M. F., Wallenstein, M. D., Boot, C. M., Denef, K., and Paul, E.: The Microbial Efficiency-Matrix Stabilization (MEMS) framework integrates plant litter decomposition with soil organic matter stabilization: Do labile plant inputs form stable soil organic matter?, Glob. Change Biol., 19, 988-995, https://doi.org/10.1111/gcb.12113, 2013.

Cotrufo, M. F., Soong, J. L., Horton, A. J., Campbell, E. E., Haddix, M. L., Wall, D. H., and Parton, W. J.: Formation of soil organic matter via biochemical and physical pathways of litter mass loss, Nat. Geosci., 8, 776-779, https://doi.org/10.1038/ngeo2520, 2015.

Craft, C., Clough, J., Ehman, J., Jove, S., Park, R., Pennings, S., Guo, H., and Machmuller, M.: Forecasting the effects of accelerated sea-level rise on tidal marsh ecosystem services, Front. Ecol. Environ., 7, 73-78, https://doi.org/10.1890/070219, 2009.

Craig, M.: Long Reach Lane at Long Marsh, Harpswell, 2015 PostProject Monitoring Report, available at: http://digitalcommons. usm.maine.edu/cbep-publications (last access: 20 May 2018), 2015.

Crosby, S. C., Sax, D. F., Palmer, M. E., Booth, H. S., Deegan, L. A., Bertness, M. D., and Leslie, H. M.: Salt marsh persistence is threatened by predicted sea-level rise, Estuar. Coast. Shelf Sci., 181, 93-99, https://doi.org/10.1016/j.ecss.2016.08.018, 2016.

Curiel Yuste, J., Baldocchi, D. D., Gershenson, A., Goldstein, A., Misson, L., and Wong, S.: Microbial soil respiration and its dependency on carbon inputs, soil temperature and moisture, Glob. Change Biol., 13, 2018-2035, https://doi.org/10.1111/j.13652486.2007.01415.x, 2007.

Davidson, E. A. and Janssens, I. A.: Temperature sensitivity of soil carbon decomposition and feedbacks to climate change, Nature, 440, 165-173, https://doi.org/10.1038/nature04514, 2006.

Davy, A. J., Brown, M. J. H., Mossman, H. L., and Grant, A.: Colonization of a newly developing salt marsh: Disentangling independent effects of elevation and redox potential on halophytes, J. Ecol., 99, 1350-1357, https://doi.org/10.1111/j.13652745.2011.01870.x, 2011.

Deegan, L. A., Johnson, D. S., Warren, R. S., Peterson, B. J., Fleeger, J. W., Fagherazzi, S., and Wollheim, W. M.: Coastal eutrophication as a driver of salt marsh loss, Nature, 490, 338-392, https://doi.org/10.1038/nature11533, 2012.
Dijkema, K. S., Kers, A. S., and Van Duin, W. E.: Salt marshes: applied long-term monitoring salt marshes, Wadden Sea Ecosyst., 26, 35-40, 2010.

Djukic, I., Kepfer-Rojas, S., Schmidt, I. K., Larsen, K. S., Beier, C., Berg, B., Verheyen, K., and TeaComposition: Early stage litter decomposition across biomes, Sci. Total Environ., 628-629, 1369-1394, https://doi.org/10.1016/j.scitotenv.2018.01.012, 2018.

Duboc, O., Dignac, M. F., Djukic, I., Zehetner, F., Gerzabek, M. H., and Rumpel, C.: Lignin decomposition along an Alpine elevation gradient in relation to physicochemical and soil microbial parameters, Glob. Change Biol., 20, 2272-2285, https://doi.org/10.1111/gcb.12497, 2014.

Feng, X., Simpson, A. J., Schlesinger, W. H., and Simpson, M. J.: Altered microbial community structure and organic matter composition under elevated $\mathrm{CO}_{2}$ and $\mathrm{N}$ fertilization in the duke forest, Glob. Change Biol., 16, 2104-2116, https://doi.org/10.1111/j.1365-2486.2009.02080.x, 2010.

Flemming, B. W. and Davis, R. A.: Holocene evolution, morphodynamics and sedimentology of the Spiekeroog barrier island system (southern North Sea), Senckenbergia maritima, 24, 117-155, 1994.

Gedan, K. B. and Bertness, M. D.: Experimental warming causes rapid loss of plant diversity in New England salt marshes, Ecol. Lett., 12, 842-848, https://doi.org/10.1111/j.14610248.2009.01337.x, 2009.

Haddix, M. L., Paul, E. A., and Cotrufo, M. F.: Dual, differential isotope labeling shows the preferential movement of labile plant constituents into mineral-bonded soil organic matter, Glob. Change Biol., 22, 2301-2312, https://doi.org/10.1111/gcb.13237, 2016.

Halupa, P. J. and Howes, B. L.: Effects of tidally mediated litter moisture content on decomposition of Spartina alterniflora and S. patens, Mar. Biol., 123, 379-391, https://doi.org/10.1007/BF00353629, 1995.

Hemminga, M. A. and Buth, G. J. C.: Decomposition in salt marsh ecosystems of the S. W. Netherlands: the effects of biotic and abiotic factors, Vegetatio, 92, 73-83, 1991.

Howison, R. A., Olff, H., Steever, R., and Smit, C.: Large herbivores change the direction of interactions within plant communities along a salt marsh stress gradient, J. Veg. Sci., 26, 11591170, https://doi.org/10.1111/jvs.12317, 2015.

Isacch, J., Costa, C., Rodriguez-Gallego, L., Conde, D., Escapa, M., Gagliardini, D., and Iribarne, O.: Distribution of saltmarsh plant communities associated with environmental factors along a latitudinal gradient on the south-west Atlantic coast, J. Biogeogr., 33, 888-900, https://doi.org/10.1111/j.1365-2699.2006.01461.x, 2006.

Janousek, C. N., Buffington, K. J., Guntenspergen, G. R., Thorne, K. M., Dugger, B. D., and Takekawa, J. Y.: Inundation, vegetation, and sediment effects on litter decomposition in Pacific Coast tidal marshes, Ecosystems, 20, 2014-2015, https://doi.org/10.1007/s10021-017-0111-6, 2017.

Johnson, D. S., Warren, R. S., Deegan, L. A., and Mozdzer, T. J.: Saltmarsh plant responses to eutrophication, Ecol. Appl., 26, 2647-2659, https://doi.org/10.1002/eap.1402, 2016.

Kearns, P. J., Angell, J. H., Howard, E. M., Deegan, L. A., Stanley, R. H. R., and Bowen, J. L.: Nutrient enrichment induces dormancy and decreases diversity of active 
bacteria in salt marsh sediments, Nat. Commun., 7, 1-9, https://doi.org/10.1038/ncomms12881, 2016.

Keuskamp, J. A., Dingemans, B. J. J., Lehtinen, T., Sarneel, J. M., and Hefting, M. M.: Tea Bag Index: a novel approach to collect uniform decomposition data across ecosystems, Methods Ecol. Evol., 4, 1070-1075, https://doi.org/10.1111/2041-210X.12097, 2013.

Keuskamp, J. A., Feller, I. C., Laanbroek, H. J., Verhoeven, J. T. A., and Hefting, M. M.: Short- and long-term effects of nutrient enrichment on microbial exoenzyme activity in mangrove peat, Soil Biol. Biochem., 81, 38-47, https://doi.org/10.1016/j.soilbio.2014.11.003, 2015a.

Keuskamp, J. A., Hefting, M. M., Dingemans, B. J. J., Verhoeven, J. T. A., and Feller, I. C.: Effects of nutrient enrichment on mangrove leaf litter decomposition, Sci. Total Environ., 508, 402410, https://doi.org/10.1016/j.scitotenv.2014.11.092, 2015 b.

Khan, N. S., Vane, C. H., and Horton, B. P.: Stable carbon isotope and $\mathrm{C} / \mathrm{N}$ geochemistry of coastal wetland sediments as a sea-level indicator, Handb. Sea-Level Res., 1, 295-311, https://doi.org/10.1002/9781118452547.ch20, 2015.

Kirwan, M. L. and Blum, L. K.: Enhanced decomposition offsets enhanced productivity and soil carbon accumulation in coastal wetlands responding to climate change, Biogeosciences, 8, 987993, https://doi.org/10.5194/bg-8-987-2011, 2011.

Kirwan, M. L. and Megonigal, J. P.: Tidal wetland stability in the face of human impacts and sea-level rise, Nature, 504, 53-60, https://doi.org/10.1038/nature12856, 2013.

Kirwan, M. L., Guntenspergen, G. R., and Morris, J. T.: Latitudinal trends in Spartina alterniflora productivity and the response of coastal marshes to global change, Glob. Change Biol., 15, 19821989, https://doi.org/10.1111/j.1365-2486.2008.01834.x, 2009.

Kirwan, M. L., Langley, J. A., Guntenspergen, G. R., and Megonigal, J. P.: The impact of sea-level rise on organic matter decay rates in Chesapeake Bay brackish tidal marshes, Biogeosciences, 10, 1869-1876, https://doi.org/10.5194/bg-10-1869-2013, 2013.

Kirwan, M. L., Guntenspergen, G. R., and Langley, J. A.: Temperature sensitivity of organic-matter decay in tidal marshes, Biogeosciences, 11, 4801-4808, https://doi.org/10.5194/bg-114801-2014, 2014.

Knorr, M., Frey, S. D., and Curtis, P. S.: Nitrogen additions and litter decomposition: A meta analysys, Ecology, 86, 3252-3257, https://doi.org/10.1890/05-0150, 2005.

Kristensen, E., Ahmed, S. I., and Devol, A. H.: Aerobic and anaerobic decomposition of organic matter in marine sediment: Which is fastest?, Limnol. Oceanogr., 40, 1430-1437, https://doi.org/10.4319/lo.1995.40.8.1430, 1995.

Latter, P. M. and Walton, D. W. H.: The cotton strip assay for cellulose decomposition studies in soil: history of the assay and development, in: Cotton strip assay: an index of decomposition in soils, edited by: Harrison, A. F., Latter, P. M., and Walton, D. W. H., Grange-over-Sands, UK, 1988.

Langley, J. A. and Megonigal, J. P.: Ecosystem response to elevated $\mathrm{CO}_{2}$ levels limited by nitrogen-induced plant species shift, Nature, 466, 96-99, https://doi.org/10.1038/nature09176, 2010.

Langley, J. A., Mozdzer, T. J., Shepard, K. A., Hagerty, S. B., and Megonigal, J. P.: Tidal marsh plant responses to elevated $\mathrm{CO}_{2}$, nitrogen fertilization, and sea level rise, Glob. Change Biol., 19, 1495-1503, https://doi.org/10.1111/gcb.12147, 2013.
Lovelock, C. E., Feller, I. C., McKee, K. L., and Thompson, R.: Variation in mangrove forest structure and sediment characteristics in Bocas del Toro, Panama, Caribb. J. Sci., 41, 456-464, ISSN 0008-6452, 2005.

Macreadie, P. I., Nielsen, D. A., Kelleway, J. J., Atwood, T. B., Seymour, J. R., Petrou, K., Connolly, R. M., Thomson, A. C., Trevathan-Tackett, S. M., and Ralph, P. J.: Can we manage coastal ecosystems to sequester more blue carbon?, Front. Ecol. Environ., 15, 206-213, https://doi.org/10.1002/fee.1484, 2017.

McKee, K. L., Cahoon, D. R., and Feller, I. C.: Caribbean mangroves adjust to rising sea level through biotic controls on change in soil elevation, Glob. Ecol. Biogeogr., 16, 545-556, https://doi.org/10.1111/j.1466-8238.2007.00317.x, 2007.

Mcleod, E., Chmura, G. L., Bouillon, S., Salm, R., Björk, M., Duarte, C. M., Lovelock, C. E., Schlesinger, W. H., and Silliman, B. R.: A blueprint for blue carbon: toward an improved understanding of the role of vegetated coastal habitats in sequestering $\mathrm{CO}_{2}$, Front. Ecol. Environ., 9, 552-560, https://doi.org/10.1890/110004, 2011.

McTiernan, K. B., Coûteaux, M. M., Berg, B., Berg, M. P., De Anta, R. C., Gallardo, A., Kratz, W., Piussi, P., Remacle, J., and De Santo, A. V.: Changes in chemical composition of Pinus sylvestris needle litter during decomposition along a European coniferous forest climatic transect, Soil Biol. Biochem., 35, 801812, https://doi.org/10.1016/S0038-0717(03)00107-X, 2003.

Morris, J. and Bradley, P.: Effects of nutrient loading on the carbon balance of coastal wetland sediments, Limnol. Oceanogr., 44, 699-702, https://doi.org/10.4319/lo.1999.44.3.0699, 1999.

Morris, J. T., Sundberg, K., and Hopkinson, C. S.: Salt marsh primary production and its responses to relative sea level and nutrients, Oceanography, 26, 78-84, 2013.

Mozdzer, T. J., McGlathery, K. J., Mills, A. L., and Zieman, J. C.: Latitudinal variation in the availability and use of dissolved organic nitrogen in Atlantic coast salt marshes, Ecology, 95, 32933303, 2014.

Mueller, P., Jensen, K., and Megonigal, J. P.: Plants mediate soil organic matter decomposition in response to sea level rise, Glob. Change Biol., 22, 404-414, https://doi.org/10.1111/gcb.13082, 2016.

Mueller, P., Granse, D., Nolte, S., Do, H. T., Weingartner, M., Hoth, S., and Jensen, K.: Top-down control of carbon sequestration: grazing affects microbial structure and function in salt marsh soils, Ecol. Appl., 27, 1435-1450, https://doi.org/10.1002/eap.1534, 2017.

Mueller, P., Schile-Beers, L. M., Mozdzer, T. J., Chmura, G. L., Dinter, T., Kuzyakov, Y., de Groot, A. V., Esselink, P., Smit, C., D’Alpaos, A., Ibáñez, C., Lazarus, M., Neumeier, U., Johnson, B., Baldwin, A. H., Yarwood, S. A., Montemayor, D., Yang, Z., Wu, J., Jensen, K., and Nolte, S.: Tea Bag Index $S$ and $k$ data of tidal wetland sites, https://doi.org/10.1594/PANGAEA.890175, 2018.

Neff, K. P., Rusello, K., and Baldwin, A. H.: Rapid seed bank development in restored tidal freshwater wetlands, Restor. Ecol., 17, 539-548, https://doi.org/10.1111/j.1526100X.2008.00415.x, 2009.

Neumeier, U. and Cheng, C.: Hydrodynamics and sediment dynamics in an ice-covered tidal flat, Coast. Sediments, 2015, 1-14, https://doi.org/10.1142/9789814689977_0083, 2015. 
Nolte, S., Müller, F., Schuerch, M., Wanner, A., Esselink, P., Bakker, J. P., and Jensen, K.: Does livestock grazing affect sediment deposition and accretion rates in salt marshes?, Estuar. Coast. Shelf Sci., 135, 296-305, https://doi.org/10.1016/j.ecss.2013.10.026, 2013.

Pendleton, L., Donato, D. C., Murray, B. C., Crooks, S., Jenkins, W. A., Sifleet, S., Craft, C., Fourqurean, J. W., Kauffman, J. B., Marbà, N., Megonigal, P., Pidgeon, E., Herr, D., Gordon, D., and Baldera, A.: Estimating global "blue carbon" emissions from conversion and degradation of vegetated coastal ecosystems, PLoS One, 7, e43542, https://doi.org/10.1371/journal.pone.0043542, 2012.

Powers, J. S., Montgomery, R. A., Adair, E. C., Brearley, F. Q., Dewalt, S. J., Castanho, C. T., Chave, J., Deinert, E., Ganzhorn, J. U., Gilbert, M. E., González-Iturbe, J. A., Bunyavejchewin, S., Grau, H. R., Harms, K. E., Hiremath, A., Iriarte-Vivar, S., Manzane, E., De Oliveira, A. A., Poorter, L., Ramanamanjato, J. B., Salk, C., Varela, A., Weiblen, G. D., and Lerdau, M. T.: Decomposition in tropical forests: A pan-tropical study of the effects of litter type, litter placement and mesofaunal exclusion across a precipitation gradient, J. Ecol., 97, 801-811, https://doi.org/10.1111/j.1365-2745.2009.01515.x, 2009.

Prescott, C. E.: Litter decomposition: What controls it and how can we alter it to sequester more carbon in forest soils?, Biogeochemistry, 101, 133-149, https://doi.org/10.1007/s10533-010-9439-0, 2010.

Roner, M., D'Alpaos, A., Ghinassi, M., Marani, M., Silvestri, S., Franceschinis, E., and Realdon, N.: Spatial variation of salt-marsh organic and inorganic deposition and organic carbon accumulation: Inferences from the Venice lagoon, Italy, Adv. Water Resour., 93, 276-287, https://doi.org/10.1016/j.advwatres.2015.11.011, 2016.
Rothwell, J. J., Futter, M. N., and Dise, N. B.: A classification and regression tree model of controls on dissolved inorganic nitrogen leaching from European forests, Environ. Pollut., 156, 544-552, https://doi.org/10.1016/j.envpol.2008.01.007, 2008.

Ryan, M. G., Melillo, J. M., and Ricca, A.: A comparison of methods for determining proximate carbon fractions of forest litter, Can. J. For. Res. Can. Rech. For., 20, 166-171, https://doi.org/10.1139/x90-023, 1990.

Schile, L. M., Callaway, J. C., Morris, J. T., Stralberg, D., Thomas Parker, V., and Kelly, M.: Modeling tidal marsh distribution with sea-level rise: Evaluating the role of vegetation, sediment, and upland habitat in marsh resiliency, PLoS One, 9, e88760, https://doi.org/10.1371/journal.pone.0088760, 2014.

Soil Survey Staff: Keys to soil taxonomy, Lincoln, NE, USA, 2014.

Swanson, K. M., Drexler, J. Z., Schoellhamer, D. H., Thorne, K. M., Casazza, M. L., Overton, C. T., Callaway, J. C., and Takekawa, J. Y.: Wetland Accretion Rate Model of Ecosystem Resilience (WARMER) and its application to habitat sustainability for endangered species in the San Francisco Estuary, Estuar. Coast., 37, 476-492, https://doi.org/10.1007/s12237-013-9694-0, 2014.

Trofymow, J., Moore, T., Titus, B., Prescott, C., Morrison, I., Siltanen, M., Smith, S., Fyles, J., Wein, R., Camiré, C., Duschene, L., Kozak, L., Kranabetter, M., and Visser, S.: Rates of litter decomposition over 6 years in Canadian forests: influence of litter quality and climate, Can. J. For. Res., 5, 789-804, https://doi.org/10.1139/x01-117, 2002.

Vasey, M. C., Parker, V. T., Callaway, J. C., Herbert, E. R., and Schile, L. M.: Tidal wetland vegetation in the San Francisco BayDelta Estuary, San Fr. Estuary Watershed Sci., 10, 1-16, 2012.

Yang, Z., Nolte, S., and Wu, J.: Tidal flooding diminishes the effects of livestock grazing on soil micro-food webs in a coastal saltmarsh, Agric. Ecosyst. Environ., 236, 177-186, https://doi.org/10.1016/j.agee.2016.12.006, 2017.

Zhang, D. Q., Hui, D. F., Luo, Y. Q., and Zhou, G. Y.: Rates of litter decomposition in terrestrial ecosystems: global patterns and controlling factors, J. Plant Ecol., 1, 85-93, https://doi.org/10.1093/Jpe/Rtn002, 2008. 